\title{
SISTEM INFORMASI MANAJEMEN SURAT POLITEKNIK GORONTALO
}

\author{
Ruly S. Sinukun ${ }^{1)}$, Roys Pakaya ${ }^{2)}$, Salman Suleman ${ }^{3)}$ \\ ${ }^{1}$ Program Studi Teknik Informatika, Politeknik Gorontalo \\ email: rulysinukun@poligon.ac.id \\ ${ }^{2}$ Program Studi Teknik Informatika, Politeknik Gorontalo \\ email: royspakaya@poligon.ac.id \\ ${ }^{3}$ Program Studi Teknik Informatika, Politeknik Gorontalo \\ email: salman@poligon.ac.id
}

\begin{abstract}
ABSTRAK
Dewasa ini perkembangan teknologi meningkat dengan pesat. Ini bisa dibuktikan dengan hampir semua kebutuhan manusia dalam sektor pekerjaan kantor telah di lakukan dengan komputer. Ini dikarenakan sifat asli manusia yang mencari sesuatu yang lebih efektif dalam melaksanakan sesuatu. Dengan niat membantu orang lain agar bisa lebih efektif dalam pekerjaan inilah yang membuat teknologi itu semakin hari semakin berkembang.Perkembangan yang pesat ini tentunya digunakan dengan sangat baik oleh pengguna. Namun, ada yang memanfatkannya dengan baik dan ada juga yang tidak. Beberapa contoh manusia sangat menggunakan teknologi dalam dunia pekerjaan adalah menulis sesuatu yang biasanya menggunakan kertas dan balpoin, kini telah bisa dengan menggunakan mesin ketik manual dan di sempurnakan oleh komputer. Walaupun komputer telah merupakan alat yang sangat familiar dengan manusia pada zaman sekarang, masih banyak juga terdapat beberapa orang atau bahkan institusi yang tidak menggunakan dengan baik. Ini dapat mengakibatkan pekerjaan menjadi lebih lambat dari yang seharusnya ketika menggunakan komputer. Beberapa masalah yang sering terjadi ketika masih menggukan teknik konfensional yang dalam artiannya masih belum menggunakan kompter adalah sering terjadinya kehilangan data, waktu yang digunakan menjadi bertambah dari yang seharusnya, dan ketika petugas berhalangan maka akan terhambat sebuah proses dalam sebuah pekerjaan. Contoh masalah yang sering terjadi di Instansi adalah terkait pengarsipan surat dan rekam jejak surat.dalam kasus seperti ini isntansi akan menggunakan yang namanya sebuah buku besar khusus untuk penulisan surat secara konfensional. Ini bisa bisa berakibat fatal apabila kehilangan buku tersebut tanpa ada cadangan atau salinan buku itu. Oleh karena masalah yang terjadi di atas maka penulis akan menjawab permasalahan itu dengan membuat sebuah aplikasi untuk pengarsipan surat. Kemudian dengan aplikasi inilah instansi akan mendaptkan kemudahan dalam mengelolah surat masuk dan keluar.
\end{abstract}

Kata Kunci: pengelolaan, manajemen, surat, masuk, keluar

\begin{abstract}
Technological development is increasing rapidly. This can be proven by almost all human needs in the sector of office work that have been done with computers. This is due to the original nature of humans who are looking for something more effective in carrying out something. With the intention of helping others to be more effective in this work that makes the technology increasingly developed. This rapid development is certainly used very well by users. However, there are those who use it well and some who do not. Humans who usually use paper and ballpoint pens are now using computers. Even though computers have become a tool that is very familiar with humans today, there are still many people or even institutions that don't use it well. This can cause the work to be slower than it should when using a computer. Some of the problems that often occur when still using conventional techniques, which in the sense is still not using a computer, is the frequent loss of data, the time spent increases as it should, and when the officer is not present, a process in a job will be hampered. Examples of problems that often occur in institutions are related to archiving letters and track record letters. In cases like this, the instance will use the name of a ledger specifically for conventional letter writing. This can be fatal if you lose the book without a backup or copy of the book. Because of
\end{abstract}


the problems that occur above, the author will answer the problem by making an application for archiving letters. Then with this application the agency will get convenience in managing incoming and outgoing mail.

Keywords: management, incoming mail, outgoing mail

\section{PENDAHULUAN}

\subsection{Latar Belakang Masalah}

Dewasa ini perkembangan teknologi meningkat dengan pesat. Ini bisa dibuktikan dengan hampir semua kebutuhan manusia dalam sektor pekerjaan kantor telah di lakukan dengan komputer. Ini dikarenakan sifat asli manusia yang mencari sesuatu yang lebih efektif dalam melaksanakan sesuatu. Dengan niat membantu orang lain agar bisa lebih efektif dalam pekerjaan inilah yang membuat teknologi itu semakin hari semakin berkembang.

Perkembangan yang pesat ini tentunya digunakan dengan sangat baik oleh pengguna. Namun, ada yang memanfatkannya dengan baik dan ada juga yang tidak. Beberapa contoh manusia sangat menggunakan teknologi dalam dunia pekerjaan adalah menulis sesuatu yang biasanya menggunakan kertas dan balpoin, kini telah bisa dengan menggunakan mesin ketik manual dan di sempurnakan oleh komputer. Walaupun komputer telah merupakan alat yang sangat familiar dengan manusia pada zaman sekarang, masih banyak juga terdapat beberapa orang atau bahkan institusi yang tidak menggunakan dengan baik. Ini dapat mengakibatkan pekerjaan menjadi lebih lambat dari yang seharusnya ketika menggunakan komputer.

Beberapa masalah yang sering terjadi ketika masih menggukan teknik konfensional yang dalam artiannya masih belum menggunakan kompter adalah sering terjadinya kehilangan data, waktu yang digunakan menjadi bertambah dari yang seharusnya, dan ketika petugas berhalangan maka akan terhambat sebuah proses dalam sebuah pekerjaan. Contoh masalah yang sering terjadi di Instansi adalah terkait pengarsipan surat dan rekam jejak surat.dalam kasus seperti ini isntansi akan menggunakan yang namanya sebuah buku besar khusus untuk penulisan surat secara konfensional. Ini bisa bisa berakibat fatal apabila kehilangan buku tersebut tanpa ada cadangan atau salinan buku itu.

Oleh karena masalah yang terjadi di atas maka penulis akan menjawab permasalahan itu dengan membuat sebuah aplikasi untuk pengarsipan surat. Kemudian dengan aplikasi inilah instansi akan mendaptkan kemudahan dalam mengelolah surat masuk dan keluar.

\subsection{Rumusan Masalah}

Dari masalah yang ada maka penulis menyimpulan masalahnya adalah sebagai berikut:

1. Bagaimana sebuah isntansi dapat mengelolah data dengan baik tanpa harus kehilangan data?

2. Bagaimana pengarsipan surat masuk dan keluar menjadi lebih baik dan teratur?

3. Bagaimana mengefisienkan waktu pekerjaan dalam pengarsipan surat?

\subsection{Batasan Masalah}

Adapun batasan masalah pada penelitian ini adalah sebagai berikut:

1. Pada penelitian ini pengarsipan surat yang di lakukan masih dalam bentuk offline

2. Hanya di khususkan untuk sebuah instansi dalam hal ini Politeknik Gorontalo

3. Penelitian ini di lakukan di lingkungan Politeknik Gorontalo

\subsection{Tujuan Penelitian}

Adapun tujuan penelitiannya adalah

1. Membuat aplikasi yang dapat mengelolah data dengan baik sehingga tidak terjadi kehilangan data

2. Membuat aplikasi yang dapat memberikan penyimpanan serta tata letak dalam data base teratur

3. Membuat aplikasi dengan fasilitas search dan print.

\section{TINJAUAN PUSTAKA}

\subsection{Pengertian Sistem Informasi}

Sistem informasi merupakan satu kesatuan sistem yang dibentuk dengan tujuan untuk melaksanakan tugas atau pekerjaan secara sistematis dalam menghasilkan sesuatu yang akan menjadi acuan pengambilan keputusan.

Pada dasarnya sistem informasi adalah satu kesatuan sistem yang ada pada sebuah perusahaan atau organisasi pekerjaan yang mana terdapat kolaboari yang terdiri dari perkumpulan manusia, infrastruktur, 
teknologi yang menghasilkan jalannya komunikasi serta prosedur berbagai jenis masalah di dalam maupun diluar yang bisa dijadikan sebagai patokan dalam menentukan keputusan berdasarkan data informasi yang terdapat pada sistem tersebut.

Sistem Informasi tidak akan dapat berjalan tanpa adanya atau dukungan prosedural dan pengaturan yang meliputi kolaborasi teknologi informasi dan berbagai kegiatan manusia yang memiliki peranan sebagai user teknologi itu sendiri. Menurut Gordon B. Davis (1991: 91) Sistem informasi adalah suatu sistem yang menerima input atau masukan data dan instruksi, mengolah data sesuai dengan instruksi dan mengeluarkan hasilnya.

Terbentuknya kegiatan prosedur Sistem Informasi diantaranya dipengaruhi oleh

1. Data collection

2. Grouping data

3. Data calculation

4. Analize issues

5. Presentation report Sedangkan target dari sebuah sistem informasi yakni :

6. Pekerjaan atau tugas dapat diselesaikan tepat waktu.

7. Kualitas pekerjaan mempunyai nilai efeseinsi dan efektivitas yang baik.

8. Pengguna diharuskan untuk lebih aktif agar memperoleh hasil yang berkualitas

9. Sistem yang dibangun lebih mudah penggunaannya

10. Luaran yang baik dan berkualitas akan mendatangkan keuntungan.

11. Meningkatkan efektifitas perekonomian

Secara umum, sistem informasi dapat didefenisikan sebagai sistem yang saling terhubung antara satu dengan yang lain secara utuh atau maksimal sehingga proses pengerjaan, penyimpanan data, tata kelola, prosedur dan sajian informasi suatu instansi atau organisasi bisa tersaji secara tepat dan akurat sehingga kedepannya bisa dijadikan sebagai referensi dalam menentukan keputusan dalam mencapai target dan tujuan yang telah disetujui bersama.

\subsection{Pengarsipan}

Pengarsipan atau arsip adalah suatu kegiatan mencatat atau merekam sumber data dan informasi dengan beragam rupa dan wujud yang dibuat oleh organisai atau instansi serta perseorangan dalam ragam pelaksanaan pekerjaan. Arsip bisa dalam bentuk surat, piagam, akta, warkat, buku, dan sebagainya, yang menjadi rujukan, referensi untuk suatu kegiatan dan pertimbangan. Seiring berkembangnya dunia teknologi, arsip dapat berwujud suara, gambar dan digital.

Arsip adalah rekaan aktivitas atau kejadian dalam berbagai ragam dan alat media berdasarkan kemajuan teknologi informasi dan komunikasi yang dikerjakan dan diterima oleh instansi, lembaga pendidikan, organisasi perusahaan, politik, kemasyarakatan, dan perseorangan dalam terwujudnya aktivitas bermasyarakat, berbangsa, dan bernegara.

Arsip merupakan Rekam yang berharga dan memiliki kualitas yang berkesinambungan karena sudah memenuhi syarat administrasi, hukum atau sejarah.

\subsection{Surat}

Surat merupakan media komunikasi yang dijadikan untuk menyampaikan berita tertulis oleh salah satu pihak kepada pihak yang lainnya. Manfaat surat adalah sebagai berikut:

1. Alat penyampaian dan permintaan;

2. Ide dan gagasan;

3. Media pengingat yang dapat dijadikan bukti tertulis;

4. Dapat dijadikan kerangka pekerjaan.

\subsection{Personal Home Page (PHP)}

Personal Home Page (PHP) merupakan scripting language yang dibuat secara unik yang dapat digunakan pada halaman web. Personal Home Page (PHP) merupakan tool pada proses pengerjaan halaman website yang dinamis, dapat memudahkan programer dalam membuat perancangan web karena banyak fitur-fitur yang fleksibel. PHP merupakan nama lain dari Hypertext Processor. Source code bahasa PHP adalah sama seperti Source code C. Bahasa PHP lebih mudah dipahami dibandingkan dengan bahasa $\mathrm{C}$ hal ini di sebabkan PHP tidak mengambil source code bahasa dari $\mathrm{C}$ yang sulit. Selain itu PHP tidak mengikutsertakan pemrograman low level dari bahasa C sebab PHP dibuat hanya diperuntukkan khusus bagi pemrograman web site dan tidak memerlukan pemrograman berbasis low level. 
Seperti halnya dalam bahasa pemrograman web yang lainnya, PHP mengeksekusi proses semua intruksi yang terletak pada script PHP di dalam webserver dan mengembalikan hasil output ke dalam webbrowser pada sisi client. PHP merupakan source code yang memiliki hasil output HTML. Biasanya hasil output ini sesuai keinginan pembuat atau programernya yang nantinya dieksekusi pada sisi back and server side. Hal ini memberikan gambrana bahwa apapun bahasa (sintaks) yang kita buat nantinya akan dijalankan pada sisi server side sedangkan outputnya akan dikirimkan ke browser yang mengirim permintaan tersebut.

\subsection{CodeIgniter}

CodeIgniter merupakan salah satu framework berbasis PHP yang sangat identik dengan catatan kaki yang sangat kecil, dirancang untuk develop yang hanya memerlukan toolkit sederhana untuk membangun aplikasi web dengan variasi yang komplit.

Dalam bahasa indonesia framework dapat diartikan sebagai "kerangka kerja". Codeigniter merupakan salah satu alat (tool) yang beroperasi pada suatu konsepsi khusus dan terbagi dalam berbagai peranan yang bisa dengan mudah dipaparkan atau dialih-fungsikan untuk membangun tujuan lain yang lebih komplit. Artinya, jika Programmer membuat aplikasi memanfaatkan sebuah framework sebagai ruang kerjanya, dia harus taat dengan segala syarat dari framework tersebut. Selanjutnya ia bisa merancang berbagai fungsi yang sulit dan kompleks dengan memanfaatkan kembali peran yang telah disediakan oleh kerangka kerja tersebut. Jadi dia tidak harus lagi menulis kembali semua souce code, Ia hanya cukup belajar aturan menggunakan kerangka (frame) yang telah disediakan oleh framework tersebut.

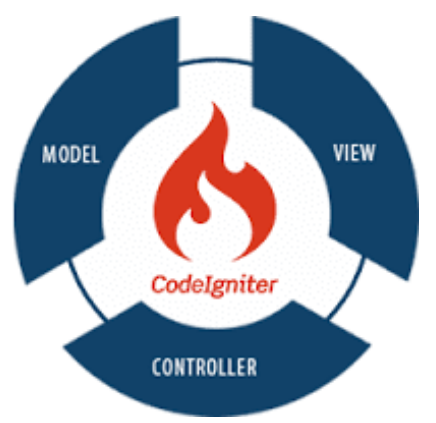

Gambar 1. Konsep CodeIgniter
1. Model merupakan bagian yang memiliki tanggungjawab pada proses database, baik itu membuat, membaca, memperbarui atau menghapus. Berisi perintah-perintah aktivitas basisdata yang bisa dipanggil oleh Controller.

2. View merupakan bagian yang memiliki tugas untuk tampilan. Pada bagian inilah yang bertanggungjawab untuk mempresentasikan informasi terhadap user. Ia terdiri dari struktur HTML yang memiliki variabel data yang akan dibawa oleh Controller.

3. Controller adalah bagian yang menghubungkan antara Miew dan Model. Ia merupakan pusat dari proses aktivitas aplikasi. Ia memiliki dari aturanaturan yang bersifat prosedural dan logikal. Saat ada permintaan yang masuk, ia akan menghandel dan memprosesnya lalu selanjutnya ditampilkan dalam View.

\subsection{Database}

Menurut Jogiyanto H.M, 1999:217, Basis data (database) adalah gabungan dari berbagai data yang saling berelasi antara satu dengan yang lainnya, tersimpan pada bagian external komputer dan akan dimanipulas dengan menggunakan perangkat lunak tertentu.

Basis data bukan hanya adalah gabungan dari file. Lebih dari itu basis data merupakan asal data yang aturannya dipakai oleh banyak user untuk berbagai aplikasi (Kendall \& Kendall, 2003:128).

Basis data bertujuan untuk:

1. Memberikan kepastian bahwa data bisa digunakan oleh pemakai pada berbagai jenis aplikasi.

2. Memelihara dan menjaga keamanan data baik ketepatan maupun kekonsistenannya.

3. Menyediakan data-data yang diperlukan oleh aplikasi secara tepat dan cepat baik sekarang maupun yang akan datang

4. Memberikan fleksibilitas bagi pemakai untuk berkembang dalam menggunakan basis data.

5. Membolehkan user dalam menanamkan konsep berfikir personalnya terhadap data tanpa memperhatikan aturan data disimpan secara bentuk atau fisik.

\section{METODE PENELITIAN}

\subsection{Tempat dan Jadwal Penelitian}

Penelitian ini di lakukakan pada masing-masing unit kerja yang berada di Politeknik Gorontalo agar 
data yang di dapatkan benar-benar akurat berdasarkan latar belakang masalah yang diajukan.

\subsection{Metode Penelitian}

Metode penelitian sebagai dasar desain dan rancangan yang menjadi acuan pada kelengkapan data dan informasi adalah:

\subsubsection{Studi Pustaka}

Pada studi literatur ini dilakukan pembelajaran dan pendalaman terhadap disiplin keilmuan yang akan diterapkan dalam membangun dan implementasi sistem. Tahapan ini dapat memanfaatkan berbagai media cetak seperti buku dan dapat pula dilakukan pada media internet.

\subsubsection{Metode Wawancara}

Pada kegiatan ini dilakukan pengumpulan informasi dan data secara langsung dari pihak pertama melalui wawancara dalam hal ini para pimpinan pengelolah Institusi dan Tim IT dari Politeknik Gorontalo.

\subsection{Teknik Pengolahan Data}

Pada langkah ini, seluruh data yang telah didapatkan melalui buku, artikel, maupun media internet serta hasil wawancara dengan pengelolah Institusi akan diolah menjadi sebuah database yang digunakan pada system yang akan dibangun.

\subsection{Alat dan Bahan Penelitian}

\subsubsection{Perangkat Keras}

1. Processor Computer Intel Core i3 dengan kecepatan 2,30 GHz

2. RAM minimal $4 \mathrm{~GB}$

3. Peyimpanan (Harddisk) minimal $500 \mathrm{~GB}$

4. Printer + Scan

\subsubsection{Perangkat Lunak}

Sistem operasi, bahasa pemrograman, dan beberapa program aplikasi penunjang yang digunakan dalam pembuatan program aplikasi sistem pakar ini adalah:

1. Sistem Operasi Windows 10 32/64 bit.

2. Aplikasi XAMP 1.7 .3 yang di dalamnya terdiri atas :

a. Apache 2.2.4, sebagai web server

b. MySQL 5.0.45, sebagai pengolah database.

c. PHP 5.2.4, sebagai bahasa pemrograman yang digunakan dalam pembuatan web.

d. PHPMyAdmin 2.11.0, sebagai database manager.
3. Aplikasi Web Browser, dalam hal ini Mozilla Firefox

\subsection{Teknik Pengujian}

Teknik pengujian yang digunakan untuk menguji program apakah sudah bebas dari kesalahan adalah teknik pengujian white box.

\subsection{Tahapan Pembuatan Program dan Jadwal Kegiatan}

\subsubsection{Tahapan Pembuatan Program}

3.6.1.1. Pengumpulan Data

Merupakan awal dari pembuatan program dengan menyelenggarakan penelitian untuk mengumpulkan data-data yang diperlukan.

\subsubsection{Perancangan Sistem}

Prosedur pengolahan data dan pembuatan model aplikasi secara manual dimana pembuatan model tersebut berdasarkan data-data yang diperoleh dari analisis kegiatan, dilakukan dengan melaksanakan penelitian secara detail terhadap semua variabel-variabel yang ada dalam aplikasi, lalu diimplementasikan kedalam perancangan sebuah sistem.

\subsubsection{Pembangunan Sistem}

Tahapan merupakan kegiatan inti dalam proses pembuatan sistem, sehingga menjadi sebuah program aplikasi yang dapat digunakan.

\subsubsection{Pengujian Sistem}

Merupakan proses terakhir dalam tahapan pembuatan program dimana kita perlu menjalankan dan menguji aplikasi tersebut agar dapat memastikan tidak ada lagi kesalahan pengambilan keputusan oleh sistem pakar maupun error coding program.

\section{HASIL DAN PEMBAHASAN \\ 4.1. Sistem berjalan}

Sebelum membahas tentang prosedur, fungsi dan tampilan pada aplikasi Sistem Informasi Manajemen Surat (SIMANSUR), terlebih dahulu akan di paparkan tentang proses aliran data (FlowChart) tentang pengelolaan surat pada Politeknik Gorontalo yang sedang berjalan. Hal dapat dilihat pada gambar di bawah ini: 


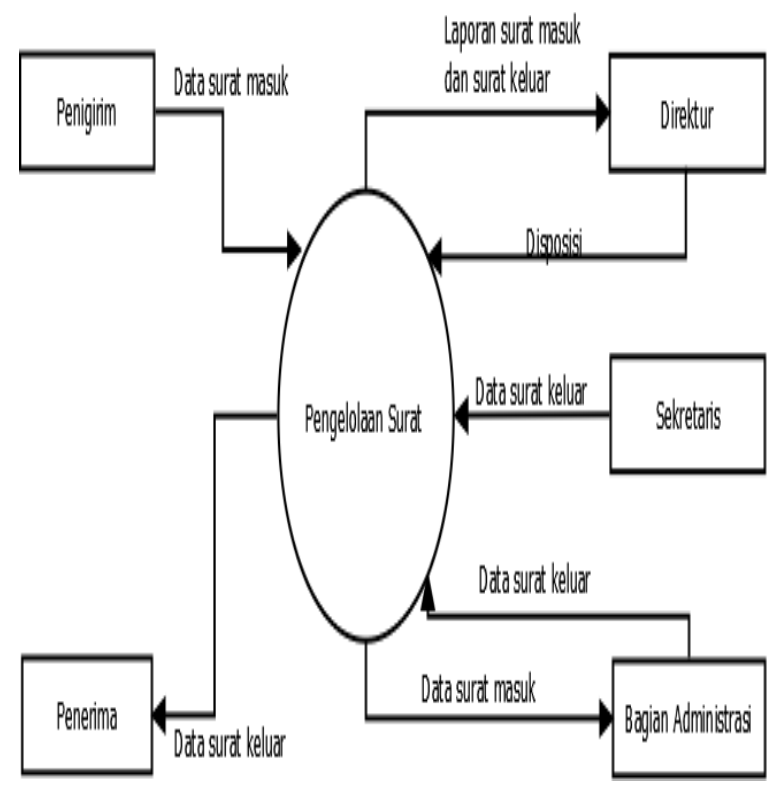

Gambar 4.1 Diagram konteks pengelolaan surat yang berjalan

\subsubsection{Data Flow Diagram pengelolaan surat yang sedang berjalan}

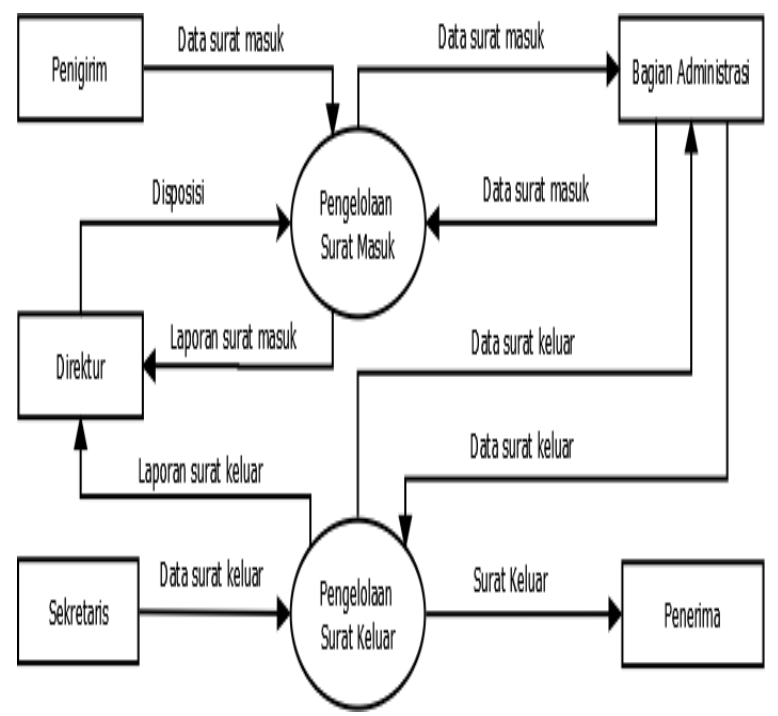

Gambar 4.2 DFD pengelolaan surat yang berjalan

\subsubsection{Flowchart proses pengolahan surat masuk yang berjalan}

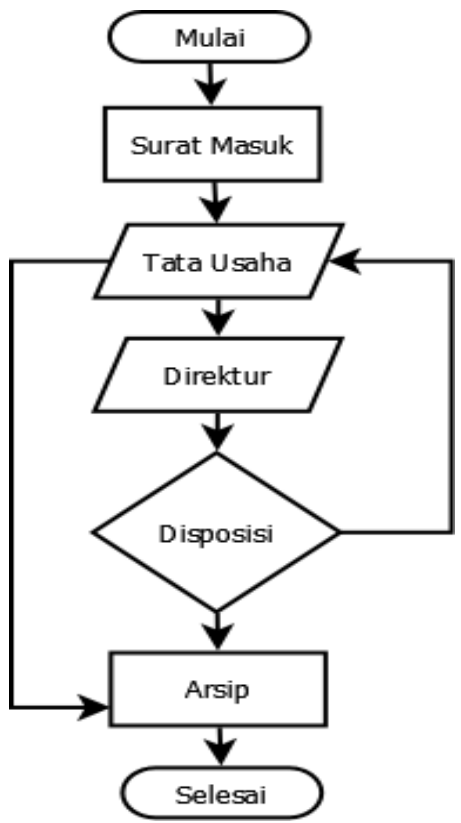

Gambar 4.3 Flowchart Proses Pengelolaan Surat Masuk yang berjalan

\subsubsection{Flowchart proses pengolahan surat keluar} yang berjalan

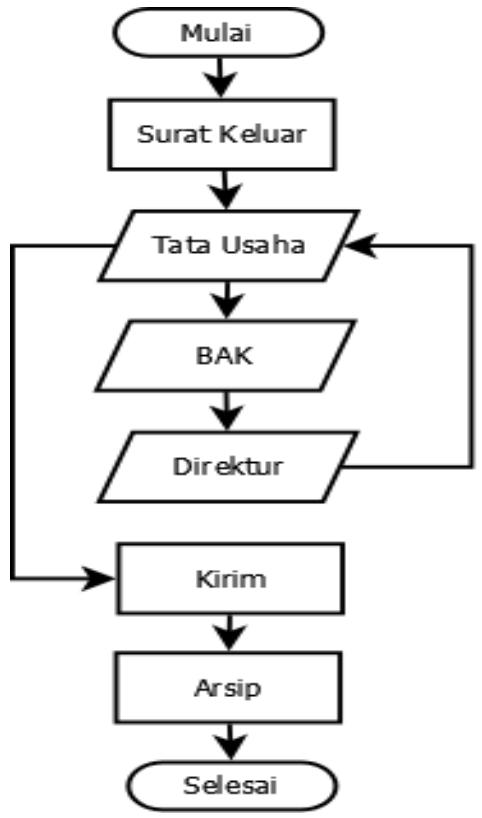

Gambar 4.4 Flowchart Proses Pengelolaan Surat Keluar yang berjalan

\subsection{Sistem yang diusulkan}




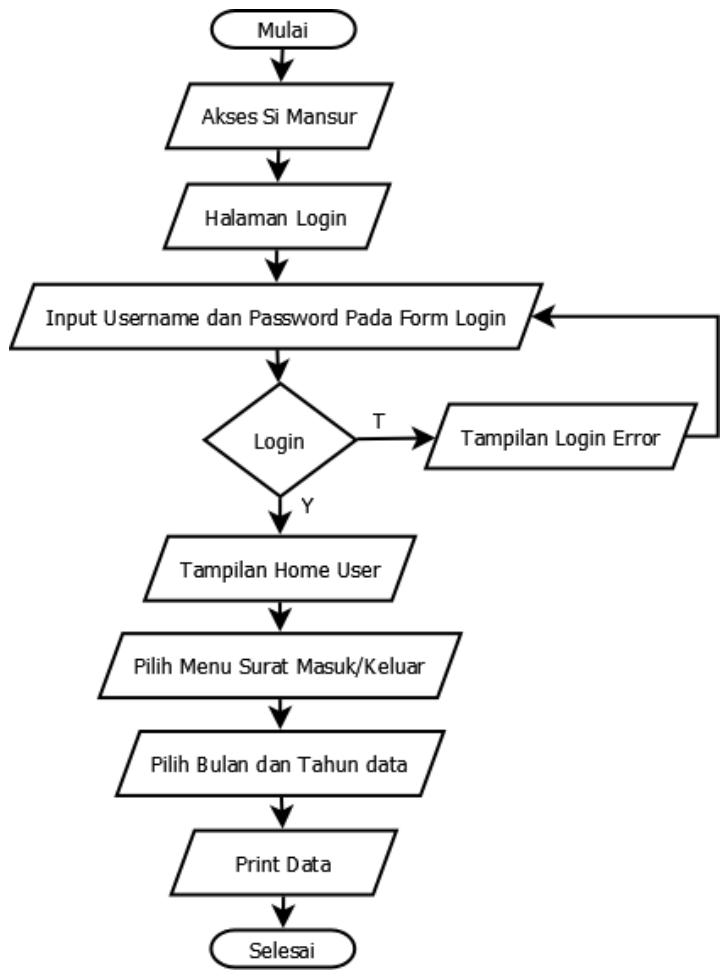

Gambar 4.5 Flowchart SIMANSUR

\subsection{Diagram konteks Sistem Informasi Manajamen Surat}

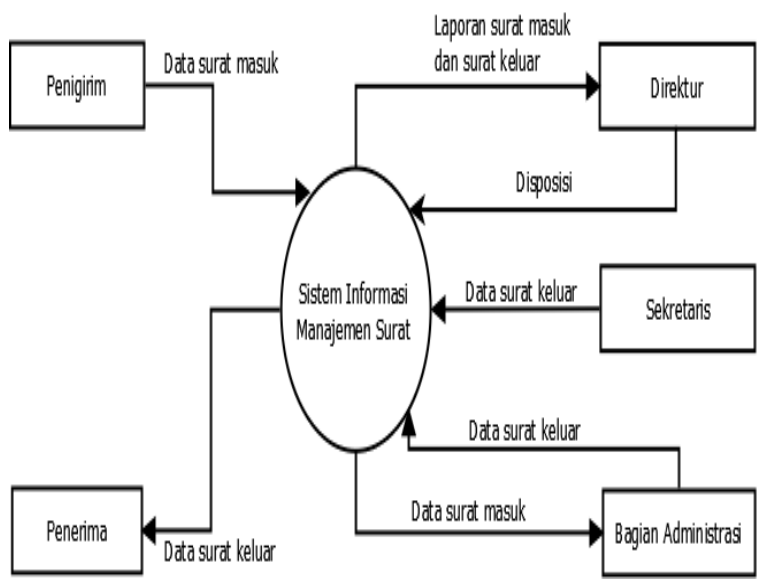

Gambar 4.6 Diagram Konteks SIMANSUR

\subsection{DFD Level 1 Sistem Informasi Manajamen Surat}

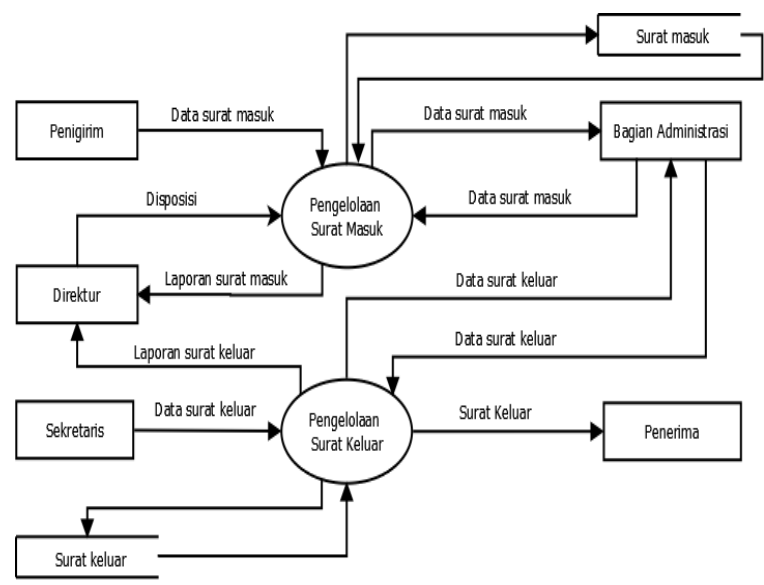

\section{KESIMPULAN DAN SARAN 5.1. KESIMPULAN}

Dengan adanya penerapan sistem informasi manajemen surat (SIMANSUR) akan memberikan kemudahan dalam pengelolaan surat masuk dan keluar pada Politeknik Gorontalo.

\subsection{SARAN}

Adapun saran dari hasil penelitian, Sistem Informasi Manajemen Surat Pada Politeknik Gorontalo adalah:

1. Penggunaan sistem informasi manajemen surat harus dioptimalkan pada semua unit agar hasil yang didapat lebih maksimal.

2. Untuk keberlanjutan penelitian dapat menambahkan beberapa fitur dalam sistem informasi diantaranya aplikasi berbasis mobile.

\section{DAFTAR PUSTAKA}

Arbie, E., 2000, Pengantar Sistem Informasi Manajemen, Edisi Ke-7, Jilid 1, Bina Alumni Indonesia, Jakarta.

Gordon B. Davis, Kerangka Dasar Sistem Informasi Manajemen Bagian 1, PT Pustaka Binamas Pressindo, Jakarta: 1991

Jogiyanto HM., Analisis dan Disain Informasi: Pendekatan Terstruktur Teori dan Praktek Aplikasi Bisnis, Andi Offset, Yogyakarta: 1999

Jogianto2 HM. 2005. Sistem Teknologi Informasi. Andi. Yogyakarta

Lani Sidharta, Pengantar Sistem Informasi Bisnis, P.T. ELEX Media Komputindo, Jakarta: 1995

Mcleod, Raymond, 2001, Sistem Informasi Manajemen, Jakarta, PT. Prenhallindo 
Muhyuzir T.D., 2001, Analisa Perancangan Sistem Pengolahan Data, Cetakan Kedua, PT. Elex Media Komputindo, Jakarta

O'Brein, James A., (2005), "Pengantar Sistem Informasi", Penerbit : Salemba 4, Jakarta.

Tata Sutabri, Sistem Informasi Manajemen, 2005, Yogyakarta, Andi 